\title{
Osteitis Condensans of the Sternal Manubrium and Ossification of the Costoclavicular Ligaments
}

\begin{abstract}
FRANCESCO PAPARO, MD, Section of Radiology, Department of Internal Medicine; MASSIMILIANO PARODI, MD, Rheumatology Clinic, Department of Internal Medicine; MATTEO REVELLI, MD; GIULIO FERRERO, MD, Section of Radiology, Department of Internal Medicine; GIACOMO GARLASCHI, MD, Professor of Radiology, Section of Radiology, Department of Internal Medicine; MARCO AMEDEO CIMMINO, MD, Professor of Rheumatology, Rheumatology Clinic, Department of Internal Medicine, University of Genoa, Genoa, Italy. Address correspondence to Dr. F. Paparo, Section of Radiology, Department of Internal Medicine, University of Genoa, Viale Benedetto XV, 6, 16132 Genoa, Italy;

E-mail: francesco.paparo.ge@fastwebnet.it. J Rheumatol 2012;39:389-90; doi:10.3899/jrheum.111128
\end{abstract}

Sternocostoclavicular hyperostosis $(\mathrm{SCCH})$, a rare, benign disorder, is frequently associated with skin lesions, but can occur without them. Patients showing only bone lesions initially may later develop cutaneous symptoms.

A 24-year-old white woman was referred for investigation of chronic pain and tenderness of the sternocostoclavicular region with minimal soft tissue swelling. The pain started 1 year before without history of trauma, low back pain, or arthritis. Examination did not reveal acne, palmoplantar pustulosis, or psoriasis. A range of laboratory examinations were normal: full blood count, erythrocyte sedimentation rate, C-reactive protein, rheumatoid factor, antinuclear antibody, serum alka- line phosphatase, and urinary hydroxyproline/creatinine ratio. HLA-B27 antigen was absent.

Computed tomography revealed dense osteosclerosis of the lower third of the sternal manubrium with bilateral ossification of the costoclavicular ligaments (Figure 1A) and erosions of the manubriosternal joint (Figure 1B). Partial ossification of the first right costochondral junction was present (Figure 1C). Magnetic resonance imaging (MRI) fast spinecho T2-weighted coronal sequence with fat saturation showed bone marrow edema involving the lower third of the sternal manubrium (Figure 2A).

The clinical and radiological features of our patient were

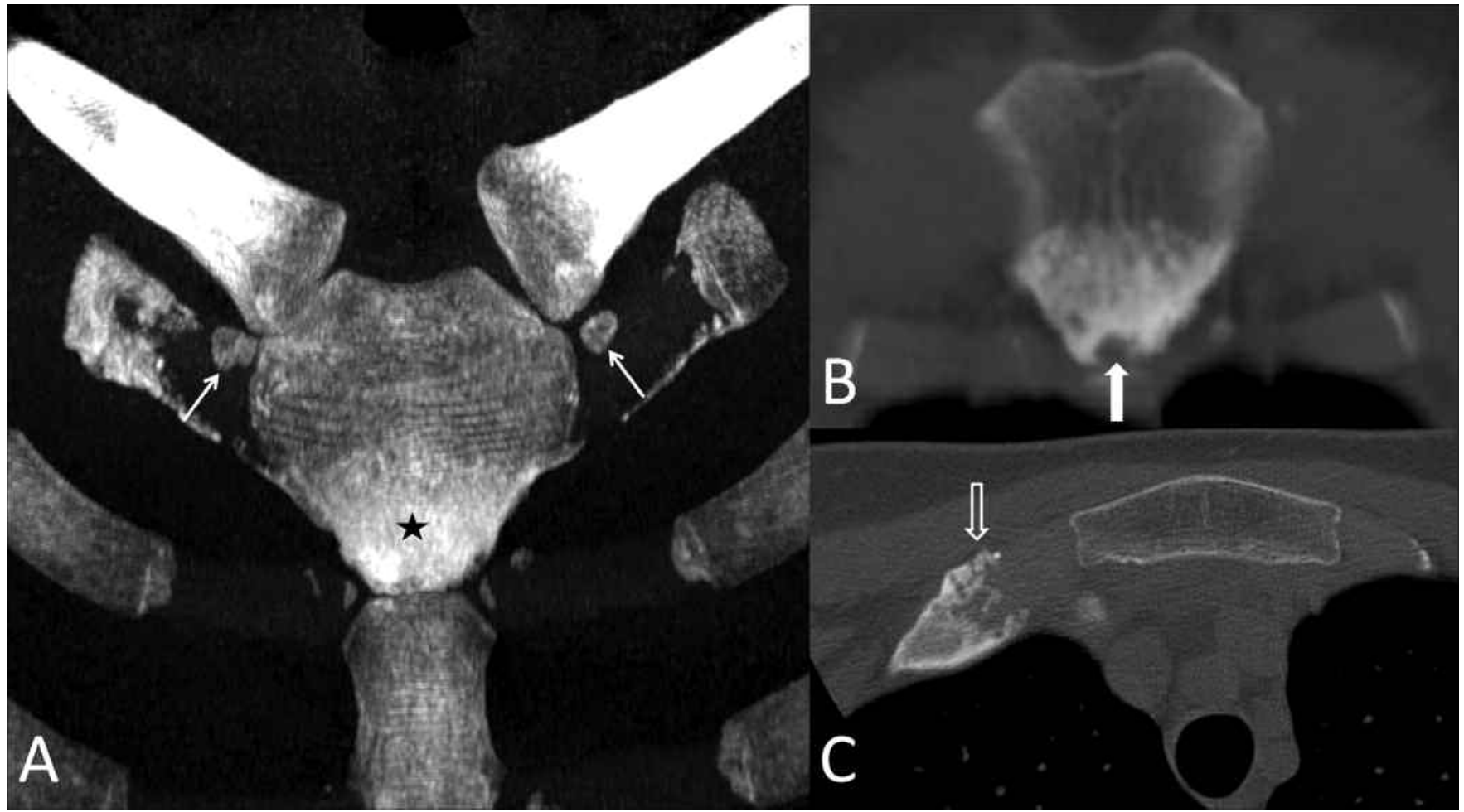

Figure 1. Volume-rendered computed tomography (CT) image (A) showing osteitis condensans of the sternal manubrium (black star) and bilateral ossification of the costoclavicular ligaments (arrows). The coronal reformatted (B) and the axial (C) CT images reveal an erosion of the sternomanubrial joint (white arrow) and partial ossification of the first right costochondral junction (black arrow).

Personal non-commercial use only. The Journal of Rheumatology Copyright $\subset$ 2012 . All rights reserved. 


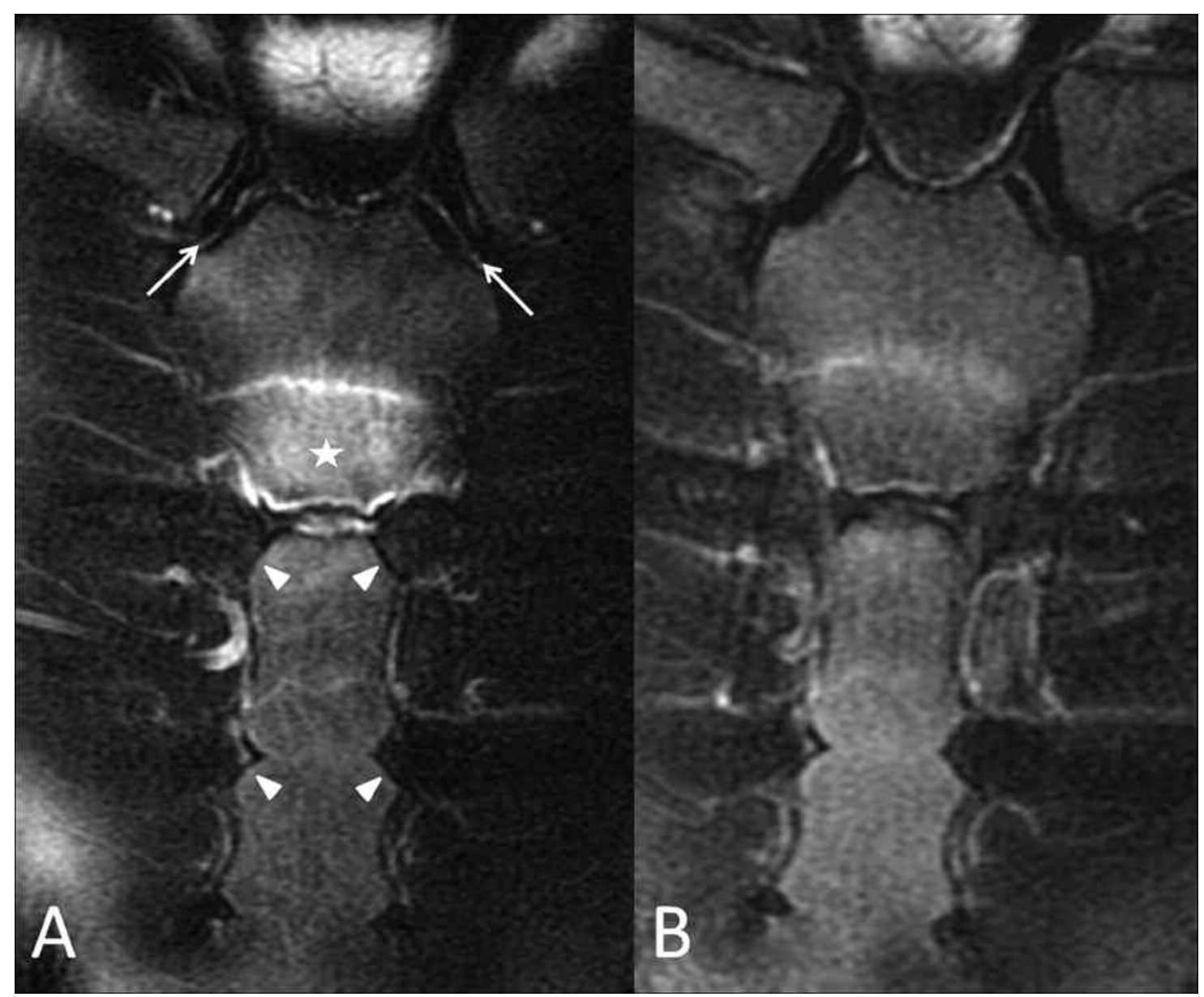

Figure 2. MRI fast spin-echo T2-weighted coronal sequences with fat saturation before (A) and after (B) 4 months of treatment with pamidronate, showing marked reduction of the bone marrow edema involving the sternal manubrium (white star in A). Both sternoclavicular joints and sternochondral junctions were unremarkable (arrow and arrowheads in A, respectively).

consistent with the diagnosis of $\mathrm{SCCH}^{1}$, which is frequently associated with peculiar skin lesions (i.e., palmoplantar pustulosis, acne conglobata, acne fulminans) and pathologically characterized by neutrophilic pseudoabscesses ${ }^{2}$.

SCCH can occur even without neutrophilic skin lesions, and patients who present with bone lesions alone may develop cutaneous manifestations over time ${ }^{2}$.

The patient was initially treated with a nonsteroidal antiinflammatory drug (meloxicam $15 \mathrm{mg} /$ day) and a cycle of 6 consecutive monthly infusions of $30 \mathrm{mg}$ of the bisphosphonate disodium pamidronate, a potent inhibitor of accelerated bone turnover ${ }^{3}$. She reported excellent relief of symptoms, and 4 months after her first pamidronate infusion, MRI showed marked reduction of sternal manubrium bone marrow edema (Figure 2B).

\section{REFERENCES}

1. Guglielmi G, Cascavilla A, Scalzo G, Salaffi F, Grassi W. Imaging of sternocostoclavicular joint in spondyloarthropathies and other rheumatic conditions. Clin Exp Rheumatol 2009;27:402-8.

2. Saghafi M, Henderson MJ, Buchanan WW. Sternocostoclavicular hyperostosis. Semin Arthritis Rheum 1993;22:215-23.

3. Colina M, La Corte R, Trotta F. Sustained remission of SAPHO syndrome with pamidronate: A follow-up of fourteen cases and a review of the literature. Clin Exp Rheumatol 2009;27:112-5. 